\section{Improving Evidence-Based Practices Through Health Literacy}

To the Editor The research findings by Wegwarth and Gigerenzer $^{1}$ is a sober reminder of the need for better communication between clinicians and patients about the appropriateness of testing and interpretation of results. The inquiries of health literacy have demonstrated poor health outcome when there is a mismatch between patient skills required for the interpretation of health information and the demands clinicians and the health care system imposed on patients. ${ }^{2}$ When demands exceed the requisite skills, patients may feel overwhelmed and retreat into silence or stop actively participating in their own care. Health literacy is not limited to just the fundamental skills of reading, writing, speaking, and numeracy and simplifying the health information, although these can be part of it. It is a continuum of multidimensional skill sets of competencies acquired over a lifetime that allows an individual to access, participate in, and make informed decisions that directly and indirectly affect health. Studies have shown that even those who have high fundamental literacy skills have poor health literacy and that up to half of US adults are not able to effectively use written material to accomplish healthrelated tasks. ${ }^{3}$

The practice of medicine is dynamic with constant shifts to diagnostic and treatment paradigms. The exponential growth of medical knowledge adds to the complexity of medical care, and there is the concern that physicians have difficulties accurately interpreting and translating evidence into clinical practice. Previous studies have shown that physicians have poor comprehension of the concepts used in the medical literature and have difficulty understanding the reported numbers (eg, results) and how to apply them to practice. ${ }^{4}$ In one study, physicians were asked to determine the probability that someone who tests positive for the fecal occult blood test has colon cancer if they were given the values of the prevalence of the disease and the sensitivity and specificity of the test. ${ }^{5}$ The answers ranged from $1 \%$ to $99 \%$. This lack of numeracy skills clearly has a negative public health impact.

It is time that we pay greater attention to the health literacy demands on both physicians and patients and take steps in enhancing medical education to improve physician knowledge and improve communication with patients. We also need to raise the standards of our secondary education so that individuals have better scientific literacy skills to comprehend the cognitive process in how physicians apply medical knowledge to clinical situations.

\section{James Song-Jeng Yeh, MD}

Author Affiliations: The Program on Regulation, Therapeutics, and Law (PORTAL), Division of Pharmacoepidemiology and Pharmacoeconomics, Department of Medicine, Brigham and Women's Hospital, Harvard Medical School, Boston, Massachusetts; Harvard School of Public Health, Boston, Massachusetts.

Corresponding Author: James Song-Jeng Yeh, MD, The Program on Regulation, Therapeutics, and Law (PORTAL), Division of Pharmacoepidemiology and Pharmacoeconomics, Department of Medicine, Brigham and Women's Hospital, Harvard Medical School, Boston, 1620 Tremont St, Ste 3030, Boston, MA 02120 (jsyeh@partners.org).

\section{Conflict of Interest Disclosures: None reported.}

1. Wegwarth $O$, Gigerenzer $G$. Overdiagnosis and overtreatment: evaluation of what physicians tell their patients about screening harms. JAMA Intern Med. 2013;173(22):2086-2087.

2. Berkman ND, Sheridan SL, Donahue KE, Halpern DJ, Crotty K. Low health literacy and health outcomes: an updated systematic review. Ann Intern Med. 2011;155(2):97-107.

3. Nielsen-Bohlman $\mathrm{L}_{\text {; }}$ Institute of Medicine (US), Committee on Health Literacy. Health Literacy: A Prescription to End Confusion. Washington, DC: National Academies Press; 2004.

4. Berwick DM, Fineberg HV, Weinstein MC. When doctors meet numbers. Am J Med. 1981;71(6):991-998.

5. Hoffrage $U$, Gigerenzer $G$. Using natural frequencies to improve diagnostic inferences. Acad Med. 1998;73(5):538-540.

In Reply Efficient health care requires informed physicians and patients, as Yeh rightly notes. Our health care system falls short on both counts. To illustrate the extent of the problem, consider cancer screening. In a representative sample of some 5000 women in 9 European countries, $92 \%$ overestimated the reduction of breast cancer mortality by mammography by a factor of 10 to 200, or they did not know. For men and PSA screening, this number was $89 \%{ }^{1}$ If it were not for the Russians, who had the most realistic estimates among the Europeans, these numbers would be even closer to $100 \%$. Among 160 German gynecologists, $80 \%$ did not understand the positive predictive value of a positive mammogram, with estimates varying between $1 \%$ and $90 \%{ }^{2}$ Among a national sample of 412 US primary care physicians, $47 \%$ wrongly thought that if more cancers are detected by a screening test, this proves that the test saves lives, and $76 \%$ mistakenly believed that if screendetected cancers have better 5 -year-survival rates than cancers detected by symptoms, this would prove that a screening test saves lives. ${ }^{3}$

Why do we have this lack of risk literacy in health care? One frequently discussed answer assumes that people are troubled with cognitive deficits that make them predictably irrational and basically hopeless at dealing with risks so that they need to be "nudged" into healthy behavior. ${ }^{4}$ Yet the fact that even fourth graders can understand the positive predictive value if information is presented in "natural frequencies" shows that the problem does not lie in stable cognitive deficits but in how information is presented to physicians and patients. This includes biased reporting in medical journals, brochures, and the media, using relative risks and other misleading statistics owing to conflicts of interest and defensive medicine that do not promote informed physicians and patients. $^{2}$

What can be done? Every medical school should teach their students how to understand evidence in general and health statistics in particular, and statistical literacy should be assessed in continuing medical education. To cultivate informed patients, elementary and high schools should start teaching the mathematics of uncertainty-statistical thinkingrather than only the mathematics of certainty. Guidelines about complete and transparent reporting in journals, patient brochures, and the media need to be better enforced, and legal systems need to be changed to protect patients and physicians alike against the practice of defensive medicine instead 
of encouraging it. ${ }^{2}$ A critical mass of informed citizens will not resolve all health care problems but can constitute a major triggering factor for better care. Informed patients will ask questions that require physicians to become better informed, who in turn will more easily see through biased reporting and attempts to create undue hopes and fears.

In the 19th century, people's health improved from a combination of clean water, better hygiene, and sufficient amounts of food. The 2oth century saw the professionalization of medicine and scientific breakthroughs, but it has left us with uninformed physicians and patients. In the 21st century, we need a third revolution to promote clean information and better physicians.

\section{Odette Wegwarth, PhD \\ Gerd Gigerenzer, PhD}

Author Affiliations: Max Planck Institute for Human Development, Harding Center for Risk Literacy, Berlin, Germany (Wegwarth, Gigerenzer).

Corresponding Author: Odette Wegwarth, PhD, Max Planck Institute for Human Development, Lentzeallee 94, 14195 Berlin, Germany (wegwarth@mpib-berlin.mpg.de)

Conflict of Interest Disclosures: None reported.

1. Gigerenzer G, Mata J, Frank R. Public knowledge of benefits of breast and prostate cancer screening in Europe. J Natl Cancer Inst. 2009;101(17):1216-1220.

2. Gigerenzer G, Gray JAM. Launching the century of the patient. In: Gigerenzer G, Gray JAM, eds. Better Doctors, Better Patients, Better Decisions: Envisioning Healthcare 2020: Strüngmann Forum Report. Vol 6. Cambridge, MA: MIT Press; 2011:1-19.

3. Wegwarth O, Schwartz LM, Woloshin S, Gaissmaier W, Gigerenzer G. Do physicians understand cancer screening statistics? a national survey of primary care physicians in the United States. Ann Intern Med. 2012;156(5):340-349.

4. Bond M. Decision-making: risk school. Nature. 2009;461(7268): 1189-1192.

\section{Drug Treatment of Obesity}

To the Editor We object to the explicit trivialization of obesity by Woloshin and Schwartz ${ }^{1}$ in their article on the weight-loss medications, lorcaserin hydrochloride and phentermine topiramate. The authors' assertion that "obesity is not an emergency-it is not even a disease"1(p618) is incorrect and of concern to millions of people whose health and quality of life are greatly diminished by this chronic disease.

In 1998, an expert panel convened by the National Institutes of Health stated that "obesity is a chronic disease, and both the patient and the practitioner need to understand that successful treatment requires a life-long effort."2(p1) Subsequently, many other organizations-including The Obesity Society, the American Association of Clinical Endocrinologists, and most recently, the American Medical Association $^{3}$-have all affirmed that obesity is indeed a chronic disease.

Yet Woloshin and Schwartz ${ }^{1}$ use their opinion that obesity is not a disease as justification for taking issue with the Food and Drug Administration's decision to approve 2 new treatments and to dismiss their benefits as unimportant.

The goal of nonsurgical treatment of obesity is to achieve and maintain a $5 \%$ to $10 \%$ loss of body weight, which has been shown to yield important improvements in health and quality of life. ${ }^{3}$ The dismissive tone of the article by Woloshin and
Schwartz ${ }^{1}$ is in contrast to another recent article on drug treatment of obesity, which noted that the new drugs may be useful adjuncts to lifestyle treatment for carefully selected patients. ${ }^{4}$

Bias against people with obesity, even from physicians, is well documented. ${ }^{5}$ Patients with obesity have difficulty finding clinicians who take their condition seriously enough to offer compassionate, evidence-based treatment.

\section{Theodore K. Kyle, RPh, MBA \\ Joseph Nadglowski Jr, BS}

Author Affiliations: Obesity Action Coalition, Tampa, Florida (Kyle, Nadglowski).

Corresponding Author: Theodore K. Kyle, RPh, MBA, Office of the Chairman, Obesity Action Coalition, 2270 Country Club Dr, Pittsburgh, PA 15241 (ted.kyle @conscienhealth.org).

Conflict of Interest Disclosures: Mr Kyle is an unpaid board member and chairman of the Obesity Action Coalition. Mr Nadglowski is an employee of the Obesity Action Coalition, a 501C3 organization that receives financial support from Vivus Inc, which markets phentermine-topiramate (Qysmia), and Eisai Inc, which markets lorcaserin hydrochloride (Belviq).

1. Woloshin S, Schwartz LM. The new weight-loss drugs, lorcaserin and phentermine-topiramate: slim pickings? JAMA Intern Med. 2014;174(4):615-619.

2. Expert Panel on the Identification, Evaluation, and Treatment of Overweight and Obesity in Adults (US). Clinical Guidelines on the Identification, Evaluation, and Treatment of Overweight and Obesity in Adults. Bethesda, MD: National Institutes of Health, National Heart, Lung, and Blood Institute; 1998.

3. American Medical Association. Resolution 420 (A-13): recognition of obesity as a disease. Proceedings of the House of Delegates 162nd Annual Meeting, June 15-19, 2013. http://www.ama-assn.org/assets/meeting/2013a /a13-addendum-refcomm-d.pdf. Accessed February 14, 2014.

4. Yanovski SZ, Yanovski JA. Long-term drug treatment for obesity: a systematic and clinical review. JAMA. 2014;311(1):74-86.

5. Puhl RM, Heuer CA. The stigma of obesity: a review and update. Obesity (Silver Spring). 2009;17(5):941-964.

To the Editor The Obesity Society, of which I am the president, is concerned with Woloshin and Schwartz's dismissal of obesity as a disease, disregard for the well-established benefits of modest weight loss, and focus on cardiovascular risk as the sole reason to treat obesity. ${ }^{1}$

The authors declare, “...obesity is not an emergency, it is not even a disease.”1(p618) Many diseases are not emergencies yet still warrant medical intervention. In fact, the American Medical Association recently joined The Obesity Society, the American Association for Clinical Endocrinologists, the World Health Organization, the National Institutes of Health, and the Food and Drug Administration (FDA), among many others, in classifying obesity as a disease. ${ }^{2}$

The authors also characterize 5\% weight loss as an insufficient benefit. Yet, science clearly demonstrates that this magnitude of weight loss improves diabetes, physical functioning, pain, and quality of life. ${ }^{3}$ A singular focus on using obesity drugs to reduce cardiovascular events misses the numerous important benefits of treating obesity on overall health.

Moreover, Woloshin and Schwartz ${ }^{1}$ exaggerate the potential adverse effects of lorcaserin hydrochloride and phentermine-topiramate, suggesting an underlying bias in their argument: that any risk (even potential) is unac- 